\title{
"A lo criollito, yo le cantaré". España y la Nueva España en la obra de Sor Juana Inés de la Cruz
}

\section{"A lo criollito, yo le cantaré". Spain and New Spain in the Works of Sor Juana Inés de la Cruz}

\author{
Sara Poot Herrera ${ }^{1}$ \\ University of California (Estados Unidos) \\ UC-Mexicanistas \\ ORCID: https://orcid.org/0000-0001-5884-7501
}

Recibido: 15-06-2021

Aceptado: 22-06-2021

\section{Resumen}

Mediante un análisis histórico y documental, se indaga en las posibles percepciones e influencias que en la vida de Sor Juana Inés de la Cruz pudo haber tenido su exposición a los incipientes movimientos sociales y culturales de la época del virreinato en la Nueva España. A lo largo de su obra, la poeta novohispana se refiere a España y a la Nueva España. De la primera, recoge la tradición literaria y la transforma, dedica poemas a los representantes de la monarquía y reconoce su propia herencia española; de la segunda, recoge la lengua nahua, el español mexicano y el eco de otras lenguas. Esta aglutinación es

\footnotetext{
${ }^{1}$ (spooth@ucsb.edu). Doctora en literatura hispánica por El Colegio de México y profesora del Departamento de Español y Portugués de la Universidad de California en Santa Bárbara. Se especializa en la literatura virreinal novohispana - especialmente en la obra de Sor Juana Inés de la Cruz- y en la literatura mexicana de los siglos XIX, XX y lo que va del XXI -sobre todo en la obra de Juan José Arreola y sus contemporáneos, y en la literatura de autoría femenina. Su trabajo sobre Sor Juana se ha enfocado en documentos de archivo. Ha sido integrante de jurados de premios nacionales e internacionales. Es cofundadora y directora de UC-Mexicanistas, asociación de especialistas en estudios mexicanos del sistema de la Universidad de California. Esta asociación, a la que pertenecen escritores e investigadores (de México, los Estados Unidos y Europa), trabaja permanentemente en la difusión de la cultura mexicana más allá de nuestras fronteras. Entre sus libros se pueden mencionar Un giro en espiral. El proyecto literario de Juan José Arreola, Universidad de Guadalajara, 1992 ( $2^{\mathrm{a}}$ ed. aum. México: Universidad Nacional Autónoma de México, 2009); Los guardaditos de Sor Juana.México: Universidad Nacional Autónoma de México, 1999; De domingo a domingo. 24 de febrero (1669-2019). A 350 años de la profesión como monja de Sor Juana Inés de la Cruz. México: Universidad del Claustro de Sor Juana, 2019.
} 
resultado de una visión integral al mismo tiempo que conciliatoria. La obra de Sor Juana Inés de la Cruz es espejo de una modernidad apuntalada en una propuesta de equidad, de tradiciones conjuntas, articuladas en el prodigio de la palabra y libertad creadora.

Palabras-clave: Nueva España, virreinato, mestizaje, lenguas originarias, loa, villancico, función poética, hilos transatlánticos, genealogía.

\begin{abstract}
Through a historical and documentary analysis, I investigate the possible perceptions and influences that Sor Juana Inés de la Cruz could have had by her exposure to the incipient cultural and social movements at the time of the viceroyalty in New Spain. Throughout her work, she refers to Spain and New Spain. From the first, she collects the literary tradition and transforms it, dedicates poems to the representatives of the monarchy and recognizes her own Spanish heritage; from the second, she collects the Nahua language, Mexican Spanish and the echo of other languages. This agglutination is the result of an integral and conciliatory vision. The work of Sor Juana Inés de la Cruz is a mirror of a modernity underpinned by a proposal of equity, of joint traditions articulated in the prodigy of the word and creative freedom.
\end{abstract}

Keywords: New Spain, Viceroyalty, Crossbreeding, Native Languages, Playlet, Carol, Poetic Function, Transatlantic Threads, Genealogy.

\title{
1. España en la casa de la Nueva España
}

Nacida en San Miguel Nepantla (del ahora Estado de México y rebautizado el lugar en 1945 como Nepantla de Sor Juana Inés de la Cruz), desde su nacimiento la niña Juana Ramírez de Azuaje estuvo rodeada de varias culturas y lenguas: en la casa familiar - abuela y abuelo maternos españoles, madre, tías y tíos criollos-, se hablaba la lengua castellana; los pobladores originarios del lugar se comunicaban en náhuatl, y una especie de lengua afromexicana era la de los trabajadores negros y mulatos de la hacienda que la orden dominicana rentaba al abuelo en Panoayan, adonde de San Miguel Nepantla se cambió a vivir Isabel Ramírez con sus tres primeras hijas, en un punto cardinal de Amecameca. En la región había también mestizos. Esta comunidad plural es una especie de mise en abyme, microcosmos representativo de la población variopinta de la Nueva España del siglo XVII.

En aquellos lugares rurales, de haciendas labriegas, pasó sus primeros años quien sería Sor Juana Inés de la Cruz, Décima Musa Mexicana. Allí 
aprendió a leer, antes de cumplir tres años, y allí se creó el hábito de su lectura, sólido cimiento de su enciclopédica cultura. Podemos imaginar a Juana niña caminando tomada de la mano de su hermana Josefa entre los surcos de la tierra -tierra de maíz y de trigo- rumbo a la de Amigas - "Aún vive la que me enseñó (Dios la guarde)", dice en su Respuesta de 1691, publicada en 1700 (Sor Juana 1957: 445)²-, imaginar a la niña Juana entrando de puntillas en la biblioteca del abuelo en aquella casa de campo en las faldas de dos volcanes, como dice en uno de sus romances:

\author{
Quizá por eso nací \\ donde los rayos solares \\ me mirasen de hito en hito, \\ no bizcos como a otras partes (Sor Juana 1951: 143-148) ${ }^{3}$.
}

Imaginar también a la niña de ocho años tomando un libro -su primer premio por haber escrito una loa sacramental ${ }^{4}$, , tal vez el primero de su propia colección, que se convertiría en su gran biblioteca, custodiada por su propia dueña junto con instrumentos musicales y otros objetos (incluso científicos, como su telescopio) en su celda del convento de San Jerónimo, de la Ciudad de México. La "celda propia" de su escritura.

A su extraordinaria inteligencia se unió el deseo del conocimiento, que fue haciendo suyo desde la lectura de sus primeros libros, alas de papel por donde le empezaron a llegar quimeras mitológicas, cultura religiosa, el estado de las ciencias de aquellos tiempos, reflexiones filosóficas, sucesos de la historia, los clásicos imprescindibles, libros sobre arte, letras impresas, que la niña leía mientras a unos pasos con la oralidad mezclada de varias voces adelantaba internamente lo que sería su "Sarao de cuatro naciones", que son: "Españoles,

${ }^{2}$ El texto original fue publicado como Respuesta de la poetisa a la Muy Ilustre Sor Philotea de la Cruz en Fama y Obras Pósthumas del Fénix de México, Décima Musa, Poetisa Americana, Sor Juana Inés de la Cruz, religiosa professa en el Convento de San Gerónimo de la Imperial Ciudad de México. Conságralas a la Magestad Cathólica de la Reyna Nuestra Señora Doña Mariana de Neoburg Baviera Palatina del Rhin, por mano de la Exc.ma Señora Doña Juana de Aragón y Cortés, Duquesa de Monteleón y Terra-Nova, Marquesa del Valle de Goaxaca, \& c. El Doctor Juan Ignacio Castorena y Ursúa, Capellán de Honor de su Magestad, Protonotario Juez Apostólico por su Santidad, Theólogo, Examinador de la Nunciatura de España, Prebendando de la Santa Iglesia Metropolitana de México. Con privilegio. En Madrid: En la Imprenta de Manuel Ruiz de Murga, à la calle de la Habada. Año de 1700, pp. 8-60.

3 Publicado en Segundo volumen de las obras de Soror Juana Inés de la Cruz, monja profesa en el Monasterio del Señor San Gerónimo de la Ciudad de México, dedicado por su misma autora a D. Juan de Orué y Arbieto Cavallero de la Orden de Santiago. Sevilla: Tomás López de Haro, Impresor, y Mercader de Libros, 1692, pp. 320-323. En su edición de las Obras completas de Sor Juana Inés de la Cruz, t. I: Lírica personal, Alfonso Méndez Plancarte clasificó y puso número a los textos de Sor Juana (a este romance corresponde el número 49). Del mismo editor, los tomos II y III; respectivamente Villancicos y letras sacras (1952) y Autos y loas (1955). Y de A.G. Salceda, el t. IV: Comedias, sainetes y prosa. Cuando cito por las cuatro ediciones del FCE anoto MP o AGS.

4 “Aprobación del Reverendíssimo Padre Diego Calleja, de la Compañía de Jesús", en Fama y Obras Pósthumas, pp. [15-35]. 
Negros, Italianos y Mexicanos", con que cierra su comedia Los empeños de una $\operatorname{casa}^{5}$. Tres coros alternan en el sarao y van presentando a las cuatro naciones. En el sarao, su autora despliega su capacidad de meter(se) en voces distintas al mismo tiempo que da muestras de asimilación de una cultura cortesana, de la que tuvo experiencia vital. Eso sucedería años después en su paso por el palacio virreinal de la ciudad de México; allí estuvo con los virreyes de Mancera donde supo y vivió la cultura palaciega. La joven Juana, muy cerca de Leonor Carreto, la virreina; la joven Juana, puesta a dialogar con cuarenta sabios, por parte de Antonio Sebastián de Mancera, virrey de la Nueva España de 1664 a 1673. La joven Juana, antes de ingresar al convento de las carmelitas (y salir de allí) y mucho antes del convento de San Jerónimo, donde profesó y (en medio de tanto quehacer conventual) escribió su obra.

La literatura de los siglos de oro español encontraría en ella a su lectora ideal y, más tarde, su continuidad, su transformación, su esplendor barroco. Por ahora, a las conversaciones en casa -la genealogía familiar envuelta de anécdotas en Sanlúcar de Barrameda, los avatares de la migración de España a la Nueva España de don Pedro, su abuelo, y de doña Beatriz, su abuela, entre muchas otras- se unía lo encontrado en los libros, y esto abría un horizonte a la imaginación, al conocimiento, incluso al sentido de pertenencia, vivido desde una conciencia española, criolla, mestiza y mexicana, y de contacto y entendimiento del pueblo y la lengua originaria, el contexto inmediato de la familia Ramírez Rendón, andaluces avecindados en una zona rural de la Nueva España, cercana a la capital, donde nacieron y crecieron sus ocho hijos y sus tres hijas; una de ellas, la madre de Sor Juana. El pequeño mundo era el gran mundo familiar, en el que no parece haber ni sombra del padre de Juana Ramírez y de Josefa y María, sus dos hermanas (después, y de otro padre, nacerían Antonia, Inés y Diego). Una familia extensa-los Ramírez, por parte de la madre-rodeaba a la niña Juana quien, "sin que bastasen castigos ni reprensiones a estorbarlo" (la Respuesta; AGS, p. 446), se las ingeniaba para leer y más leer, ejercicio y vocación intelectual que se adelantó a su elección religiosa.

Para Juana Ramírez, los libros fueron su apertura al mundo, antes de su experiencia vital en la capital novohispana: libros entre los aperos de labranza -cultivo de la tierra y cultivo del espíritu-, letras descifradas entre ruidos de picos y palas, sonidos de animales, olores de la cocina, "con todas las otras habilidades de labores y costuras que deprenden las mujeres", entre mezclas de lenguas, ilusiones por ir a la "Universidad y Escuelas en que se estudiaban las ciencias" (la Respuesta; AGS, p. 446).

El libro, emblema de sabiduría en pleno campo, al girar sus hojas en las manos pequeñitas, fue girando las ilusiones, allende los mares estaba España ("La primera luz que rayó de su ingenio fue azia los versos españoles"

\footnotetext{
${ }^{5}$ Segundo volumen, pp. 526-532; AGS, pp. 174-184.
} 
(escribió el Padre Calleja en su Aprobación a la Fama [p. 15]) y, a unas quince leguas (alrededor de 60 kilómetros) de Amecameca (en lengua náhuatl quiere decir "lugar donde los papeles señalan o indican"), estaba la capital de la Nueva España, a donde poco tiempo después llegó Juana Ramírez. ¿A qué edad llegaría? Ella misma dice (recordando el mucho provecho que había sacado de los libros): "de manera que cuando vine a Méjico, se admiraban, no tanto del ingenio, cuanto de la memoria y noticias que tenía en edad que parecía que apenas había tenido tiempo para aprender a hablar" (la Respuesta; AGS, p. 446).

En su Respuesta de 1691, Sor Juana revisita su infancia, observa de lejos a la niña que fue, su afán de leer-despicar libros -, pese (dice) a regaños y castigos. Las raíces de su saber "universal" se dieron en Nepantla/Panoayan/ Amecameca; sus ramas se extendieron en la capital de la Nueva España; sus frutos fueron las ediciones sueltas en la Nueva España y las ediciones antiguas en España, aquel lugar de los abuelos, de aquellos autores que reconocía por sus libros. La personalidad de quien sería personaje extraordinario de la historia de México (aparte su genialidad) se urdía entre cimientos españoles, novohispanos; éstos (aquéllos también) heterogéneos, históricos, cambiantes y vivos, a los que ella también pertenecía.

Respecto a la formación digamos sistemática, ningún aprendizaje negó el anterior y todos juntos fueron el tronco común de una creación que comenzó con la lectura párvula en un pueblo originario de México, que recreó la voz de su origen en el estribillo (MP 284) de un villancico donde al niño divino -“ ‘Déjenlé/ que a lo criollito, yo le cantaré "-, que se "personificó" real e idealmente (se han leído como rasgos autobiográficos) en Leonor de Los empeños de una casa, quien en un largo parlamento desde Toledo dice:

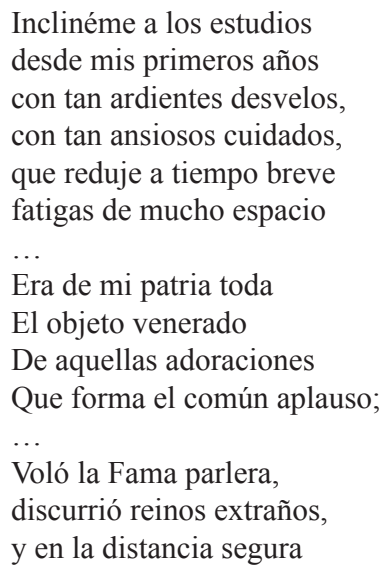


acreditó informes falsos ${ }^{6}$

Voz de Sor Juana que fue clásica en sus versos y autos sacramentales, religiosa en sus villancicos, política en su Neptuno Alegórico (1680), profana en sus comedias, lírica en sus sonetos y otros poemas, apologética en sus loas, teológica en su Carta Athenagórica, autobiográfica en su Respuesta. Los "granitos de su voz" de niña empezaron a crecer con el tambor de los volcanes y a desparramarse en el color amate de sus libros. Si hay textos sorjuaninos en los que prevalecen ciertos temas y tópicos, con su particular tratamiento -tradición y transformación-, lo fundamental es su acto de creación a partir del cual la obra cobró una materialidad excepcional, resultado de una escritura poderosa, un telar de hilos heterogéneos entrelazados desde el genio y el ingenio, la intelectualidad, la cultura libresca, el entendimiento de las cosas, el afecto, el contexto, la tradición y la herencia: ésta vino en línea directa de España y sentó bases en la Nueva España, en su contexto, sus realidades sociales.

La voz criollita villanciquera cantó en distintos tonos y tonadas, su mano escribió no sólo prosa literaria, poesía y teatro, sino que escritura y escritora "sin par" (ave fénix) explicitaron su punto de vista del mundo, del conocimiento (ejemplar su Primero Sueño), de la condición de la mujer en un contexto masculino, su conciencia americana y el reconocimiento de sus orígenes familiares -paternos. también-, hechos visibles en la dedicatoria del Segundo volumen (1692) de Soror Juana Inés de la Cruz Religiosa professa en el Monasterio N.P. San Gerónimo de México Al Señor Don Juan de Orúe y Arbieto, Cavallero del Orden de Santiago, O.D.C.:

\begin{abstract}
[...] Yo en estos papelillos, que a V.m, dedico, llevo muy diverso fin [...] porque siendo, como soy Rama de Vizcaya, y Vm. de sus nobilísimas familias de las Casas de Orue y Arbieto, vuelban los frutos a su tronco, y los arroyuelos de mis Discursos tributen sus corrientes al Mar a quien reconoce su Origen. Unde exeunt flumina revertuntur. Yo me holgara, que fuessen tales, que pudiessen honrar, y no avergonzar a nuestra Nación Vascongada; pero no extrañará Vizcaya, el que se le tributen los hierros que produce, y más quando llevan la disculpa de ser obra, no sólo de una Mujer, en quien es dispensable qualquier defecto, sino de quien [...] nunca ha sabido, cómo suena la viva Voz de los Maestros, ni ha debido a los oídos, sino a los ojos, las especies de la Doctrina en el mudo magisterio de los libros.
\end{abstract}

Eso fue en la dedicatoria del Segundo volumen (s/p), publicado en Sevilla en 1692. Su autora, que declara su condición autodidacta, se asume como descendiente vasca, lo que había puesto en voz de la Voz en Prosigue la Introducción de las coplas de los Villancicos, que se cantaron en la Santa Iglesia Metropolitana de México, en honor de María Santíssima Madre de Dios, en su

\footnotetext{
${ }^{6}$ Segundo volumen, pp. 465-469; AGS, pp. 36-45.
} 
Assumpción Triunfante, y se imprimieron en el año de 1685:

Voz. Pues que todos han cantado, yo de campiña me cierro:

que es decir, que de Vizcaya

me revisto, dicho, y hecho.

Nadie el Vasquenze mormure

que juras a Dios eterno,

que aquélla es la misma lengua

cortada de mis abuelos ${ }^{7}$.

Esos abuelos -tatarabuelos, cuyos descendientes llegaron a las Islas Canarias- serían por parte de la línea del padre de Sor Juana, como se sugiere

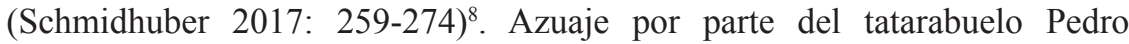
(¿remotos italianos?, me pregunto) y Lezcano por parte de la tatarabuela Jerónima (Lezcano, apellido vasco). La mención de Sor Juana respecto a su origen vascuence es literaria en el villancico de 1685 y "marca de origen" en su dedicatoria del Segundo volumen de 1692.

$\mathrm{Su}$ formación familiar, sin embargo, estuvo ligada fundamentalmente a su línea materna. El padre y la madre de Isabel Ramírez, madre de Sor Juana, fueron andaluces. Esa genealogía por parte de la madre fue su marco de referencia familiar al llegar a la Ciudad de México; la biblioteca de su abuelo Pedro Ramírez, su referencia libresca. Una y otra desarrolladas fuera de la capital de la Nueva España, en el medio rural donde Juana (Juanita) había nacido, entre olores de campo, pieles de matices distintos, la lengua castellana, los mexicanismos, el náhuatl, los ecos africanos, las costumbres mezcladas, la libertad campirana, al mismo tiempo que el anhelo de acercarse a las ciencias, a la inalcanzable universidad, a las noticias del mundo.

La niña Juana Ramírez de Azuaje inicia una nueva vida en la ciudad de México: llevaba con ella los secretos de su comunidad -pueblo originario, podemos decir-y los anhelos de su afán de saber-su originalidad manifiesta. En el horizonte de su formación dos geografías apuntalaban su historia: la España de sus abuelos y la Nueva España de la que eran primera generación en México su madre, sus dos tías y sus ocho tíos. Juana Ramírez y sus hermanas eran segunda generación: más criollas que españolas (aunque lo eran) y más mexicanas que criollas (lo eran también). Esa sucesión, ese estar en dos mundos, encontró en

\footnotetext{
${ }^{7}$ En Inundación Castálida, pp. 238-239. Antes en México, en edición aislada de los Herederos de la Viuda de Calderón, 1685. En la portada de esta edición se anota con letra manuscrita que son de Sor Juana Inés de la Cruz. En el juego de villancicos de la Asunción (1685) estos versos corresponden al Villancico VIII, Ensalada. Véase MP, t. II: Villancicos y letras sacras, pp. 94-98, vv. 103-106.

${ }^{8}$ Guillermo Schmidhuber hace la relación por medio del apellido Lezcano de quien sería tatarabuela de Sor Juana (la referencia en p. 269).
} 
Juana no una disyuntiva sino una conjunción, explícita en su obra. La cadena de conjunciones dio lugar a una multiplicación de signos culturales inscritos en la obra, que sobrepasó lo literario, y en la vida de Sor Juana Inés de la Cruz.

\section{Con los tíos y en Palacio virreinal: Nueva España y España de la mano}

La residencia de María Ramírez (hermana mayor de la madre de Sor Juana) y de su esposo Juan de Mata fue la primera casa donde ya en la Ciudad de México vivió Juana Ramírez. No se sabe con exactitud cuándo llegó a la capital de la Nueva España (sería en la segunda mitad de los años cincuenta del siglo XVII, después de que muriera su abuelo en 1656), ni cuándo ni cómo pasaría a vivir a palacio virreinal. El cómo no lo sabemos y respecto al cuándo tuvo que ser posterior al 15 de octubre de 1664, cuando los virreyes de la Nueva España -Antonio Sebastián de Toledo Molina y Salazar, $2^{\circ}$ marqués de Mancera, y Leonor Carreto, su esposa- tomaron posesión formal del virreinato (Felipe IV había dado ese cargo al virrey de Mancera, cuyo mandato terminaría en 1673). Casi un año después -el 17 de septiembre de 1665- murió en España el rey Felipe IV. Según el Diario de sucesos notables de Antonio de Robles (Robles 1972: 18-20), en México apenas se supo el domingo 16 de mayo de 1666. Para las fechas de la noticia de la muerte de Felipe IV (o en la misma fecha de su muerte), la joven Juana Ramírez ya estaría en palacio, protegida por los virreyes de Mancera, impresionados por la capacidad intelectual de quien poco tiempo atrás había llegado a la capital novohispana. A las referencias familiares españolas y a las lecturas "universales", se juntaron las noticias y costumbres cortesanas, y la joven nacida en Nepantla, vecina luego de Panoayan, allí en Amecameca, y más tarde de la capital novohispana, vivió "de cerca" la noticia de la muerte de Felipe IV, de quien era cercano el virrey de Mancera. En España, moría el rey; en la Nueva España, nacía una poeta.

$\mathrm{Su}$ genio poético se puso de manifiesto en su soneto “ ¡Oh, cuán frágil se muestra el ser humano/ en los últimos términos fatales", primer soneto del que se tiene noticia de su autoría y que podría haber sido escrito en 1666, y tendría sentido que así lo fuera debido a la noticia oficial del fallecimiento del rey. Este primer soneto, que posiblemente circularía en versión manuscrita, se imprimió por primera vez en 1692 en Sevilla, en el Segundo volumen de las obras de Soror Juana Inés de la Cruz: 


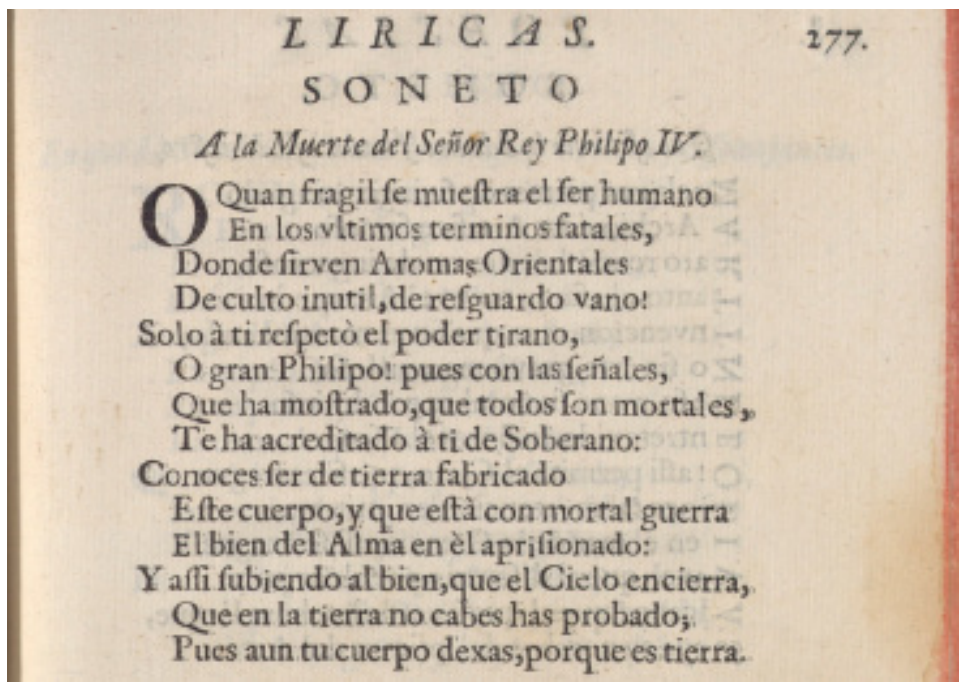

Primer soneto: A la muerte de Felipe IV: “Oh, cuán frágil se muestra el ser humano"

¡Oh, cuán frágil se muestra el ser humano

en los últimos términos fatales,

donde sirven aromas Orientales

de culto inútil de resguardo vano!

Sólo a ti respetó el poder tirano,

¡oh gran Filipo!, pues con las señales

que ha mostrado que todos son mortales,

te ha acreditado a ti de Soberano.

Conoces ser de tierra fabricado

este cuerpo, y que está con mortal guerra

el bien del alma en él aprisionado;

Y así, subiendo al bien que el Cielo encierra,

que en la tierra no cabes has probado,

Pues aun tu cuerpo dejas porque es tierra.

El primer poema de una joven letrada era dedicado al gran monarca de España: soneto perfecto, reflexión inicial sobre el final de la vida para enseguida dirigirse al rey, a su poder en tierra y a su reconocimiento del alma infinita y del cuerpo que es terrenalmente mortal. La filosofía hecha poema, y el soneto, filosofía. Era el principio de una ristra de poemas de "corte monárquico", escrito éste seguramente en el palacio virreinal de la ciudad de México, donde su autora vivió hasta mediados de 1667, cuando ingresó al convento de las carmelitas. Profesó como monja novicia el 14 de agosto de 1667 y el 18 de noviembre de ese año salió de este convento. 
Anteriormente, en su estancia en el palacio virreinal, Juana Ramírez aprendió el protocolo, supo de costumbres palaciegas, aprendizaje que puso en práctica en poemas "de la corte", en sus comedias de enredo. Sin embargo, en su soneto a Felipe IV, la voz poética no manifiesta la visión que de España tiene su autora, sino que su poema es plenamente literario, artificio del lenguaje, dominio métrico, perfecta combinación temática y formal. Es reflexión sobre el final de la vida, eso sí, de la vida del rey, al que "respetó el poder tirano" y cuyo cuerpo al morir quedó en la tierra, que de eso era. La autora del soneto tendría 15 o 18 años de edad; el poema, el iceberg de su genio.

Antes de entrar en el convento de San Jerónimo (allí estaba a principios de 1668), la joven escribió otro soneto, que fue su primer poema publicado: "Suspende, cantor Cisne, el dulce acento", dado a conocer por el Pbro. Diego de Ribera en $1668^{\circ}$. Tanto el soneto a Felipe IV como este soneto del libro de festejos a la Catedral de México de fines de 1667 sorprenden por su virtuosismo, su abstracción, el arte perfecto de la creación. En ellos, no está en juego ninguna visión sobre España o la Nueva España (su árbol genealógico, "entrambas" ramas), sino es el despliegue de la función poética del lenguaje. Su autora participaba ya en los círculos criollos intelectuales de la Ciudad de México, lo que era una excepción. Su ingreso a dicho círculo fue antes de profesar como monja jerónima (febrero de 1669); el inicio de su muy amplia cultura libresca, antes de llegar a la Ciudad de México; su genio, toda la vida.

\section{Ya en el convento}

En los primeros años del convento, por encargo de la Iglesia, Sor Juana Inés de la Cruz escribió y publicó juegos de villancicos, compuso loas y, por invitación del cabildo eclesiástico, ideó el Neptuno Alegórico, arco triunfal instalado en la Catedral de la Ciudad de México para dar la bienvenida a los segundos virreyes (1680-1686) con quienes entró en contacto: Tomás Antonio de la Cerda y Aragón, Marqués de la Laguna, y su esposa, María Luisa Manrique de Lara, condesa de Paredes. Desde el claustro la monja jerónima se daba a conocer pública y popularmente con sus villancicos, tradición de la "vieja España", heredada en la "nueva", que en su momento Sor Juana transformó a su manera, al insertar (otros lo hicieron antes y de modo distinto) el tocotín mestizo, como cierre de los villancicos a la Asunción de la Virgen en 1676; al combinar la lengua náhuatl, con el español, como lo hizo con los

\footnotetext{
${ }^{2}$ Poética descripción de la pompa plausible que admiró esta nobilísima Ciudad de México en la suntuosa dedicación de su hermoso, magnifico, y ya acabado templo, celebrado jueves 22 de diciembre de 1667, conseguida en el feliz y tranquilo gobierno del virrey Marqués de Mancera. México: Francisco Rodríguez Lupercio. En la edición de Méndez Plancarte, el número de poema es el 202, pp. 307-308. Méndez Plancarte lo cataloga como Extra Opera omnia (p. 548).
} 
villancicos a San Pedro Nolasco en 1677. Al poner a dialogar a un negro y a un indio, a orquestar varias lenguas. Si no novedad en la inserción de elementos diversos, sí genialidad, en Sor Juana Inés de la Cruz quien enriquece el género villanciquero en cuanto a la creación de juegos completos de villancicos.

Precisamente sus primeros villancicos -a la Asunción-, cantados en la Catedral Metropolitana de la Ciudad de México, son un juego magistral de piezas de engranaje perfecto ${ }^{10}$. Sor Juana se estrena (más que profesional) en 1676, cuando en la catedral metropolitana de la capital de la Nueva España se cantan sus villancicos a la Asunción. Un ejemplo de la inserción del náhuatl es cuando después de "prosigue la introducción" sigue el tocotín:

\author{
Los Mejicanos alegres \\ también a su usanza salen, \\ que en quien campa la lealtad \\ bien es que el aplauso campe; \\ y con las cláusulas tiernas \\ del Mejicano lenguaje, \\ en un tocotín sonoro \\ dicen con voces süaves
}

\title{
TOCOTÍN
}

-Tla ya timohuica

totlazo Zuapilli

maca ammo, Tonantzin, titechmoilcahuíliz ${ }^{11}$.

...

Su autora ingresa a la tradición villanciquera española y novohispana (visión doble y única), con sus juegos completos de villancicos -excepcional aporte al género- y el modo de introducir elementos polifónicos y multilingüísticos, no sólo enriquece un género de época sino lo convierte en un género mayor. Cierra este juego de villancicos una petición a la Virgen: no nos olvides. En el caso de Sor Juana el "no olvido" es deuda, es memoria, es identidad, es movimiento de traslación de una lengua a la otra y de los elementos de una en la otra. La tradición literaria-Góngora, Lope...- es una parte de la moneda de la herencia hispánica; la otra, es de la lengua poética originaria, el náhuatl, que aquí se asoma y cierra el villancico donde además se crea con líneas en latín: asamblea

${ }^{10}$ Los componentes de este juego de villancicos son: Primero nocturno: villancico I, coplas; villancico II y estribillo (latín); villancico III y estribillo. Segundo nocturno: villancico IV y coplas; villancico V y estribillo; villancico VI -jácara-, estribillo y coplas. Tercero nocturno: villancico VII estribillo, coplas -quintillas; villancico VIII -ensaladilla, Introducción -jura-, coplas -reina-, prosigue la introducción, negrillos, estribillo, prosigue la introducción, tocotín.

${ }^{11}$ Si ya te vas,/ nuestra amada Señora,/ no, Madre nuestra,/ Tú de nosotros te olvides./ Aunque en el cielo/ mucho te alegrarás,/ ¿no acaso alguna vez/ harás memoria? (trad. de Ángel María Garibay). Sor Juana tiene otro villancico a la Asunción, de 1687. 
de lenguas que celebran la asunción de la Virgen, figura intelectualizada en los primeros villancicos de la monja de San Jerónimo.

Del mismo año de estos villancicos a la Asunción, son los de la Concepción $(1676)^{12}$, también de su autoría. Una vez más, el género, español en sus inicios, se enriquece con el cruce de culturas y la adecuación al contexto novohispano que aquí aparece. En las coplas se canta:

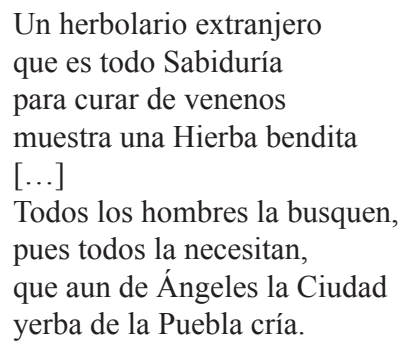

Por una parte, la segunda ciudad de la Nueva España-Puebla- es nombrada en el villancico, que se hace "local", sostenido en "una hierba bendita". Por la otra, éste termina con un diálogo "Entre un negro y la música castellana":

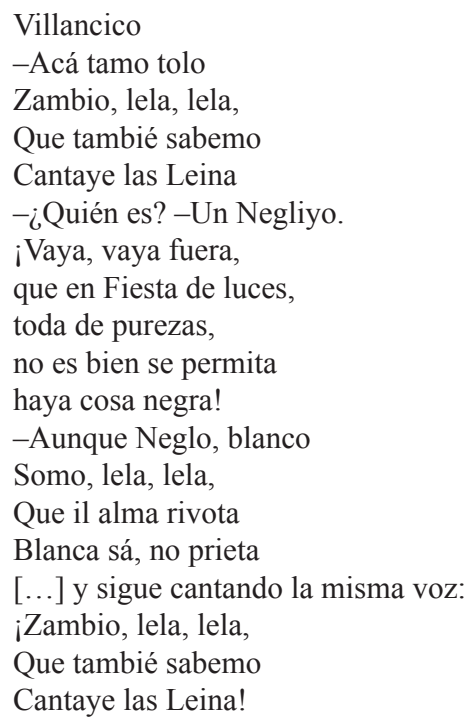

-Acá tamo tolo

Que tambié sabemo

Cantaye las Leina

-¿Quién es? -Un Negliyo.

¡Vaya, vaya fuera, que en Fiesta de luces, toda de purezas, no es bien se permita haya cosa negra! -Aunque Neglo, blanco

Somo, lela, lela, Que il alma rivota Blanca sá, no prieta [...] y sigue cantando la misma voz: ¡Zambio, lela, lela, Cantaye las Leina!

${ }^{12}$ El juego de villancicos consta de Primero nocturno: villancico I, estribillo, coplas; villancico II, estribillo, redondillas: villancico III.- Diálogo, estribillo. Segundo nocturno: villancico IV, coplas, estribillo; villancico V, coplas, estribillo; villancico VI.- Jácara, estribillo, coplas. Tercero nocturno: villancico VII, coplas. Villancico VIII: (entre un Negro y la Música Castellana), coplas. 
Se diría que es la tradición, y lo es. Sor Juana la imita, la transforma, se la apropia y desapropia para hacer escuchar esa voz colectiva, plural, "que tambié sabemo". Con esas coplas, concluye el villancico. Vendrían otros villancicos, a la par que loas y homenajes. En casi todos hay un cruce de culturas en el que observamos cada una en sí misma y articulada a la vez con las otras.

Es la segunda mitad del siglo XVII, ya han pasado más de cien años de haberse iniciado el período virreinal: sobre la fundación originaria, se imbrica la cultura hispánica y "entrambas" otras culturas están vivamente presentes. Es un siglo religioso y político a la vez y, desde el convento de San Jerónimo, la creación literaria de Sor Juana Inés de la Cruz se conoce y reconoce. Más de una vez, se encuentran textos suyos en publicaciones colectivas -de Diego de Ribera, de Carlos de Sigüenza y Góngora.

En Triunfo Parthénico (1682) de Carlos de Sigüenza y Góngora, publicación de certámenes poéticos, hay un romance dedicado al Emblema IV, que ganó Juan Sáenz del Cauri, esto es, Sor Juana Inés de la Cruz, lo que ya se sabía y que en 1926 -informa Méndez Plancarte (notas al t. I de su edición de las Obras completas de Sor Juana Inés de la Cruz, p. 390) volvió a notar Manuel Toussaint. El anagrama es perfecto, como lo es el propio romance (MP: 22, pp. 65-67; se indica que es Extra Opera omnia). Veamos el Triunfo Parthénico ${ }^{13}$ :

\section{Diofe el primer lugar al delicadiffimo numen de $\mathcal{D}$. Inan} Saenz del Catri, que redujo el afumpto à eftas acordes, y nu. merofas cadericias.

\section{Romance.}

\section{$Q$ Vando invietiffimo Cerda A el Aguila de MARIA Dedican tiernos aplaufos Aclamaciones fertivas:}

Quando celebran alegres Su puta luz matutina De tan remontiadas plumas Las bien logradas fatigas: $\mathrm{Ff}$

fol. $113 \mathrm{r}$

${ }^{13}$ Carlos de Sigüenza y Góngora, Triunfo Parténico que en las Glorias de María Santísima inmaculadamente concebida... Copio del Portal de la Biblioteca Cervantina: http://www.cervantesvirtual. com/obra-visor/triunfo-partenico-que-en-glorias-de-maria-santisima-inmaculadamente-concebidacelebro-la-pontificia-imperial-y-regia-academia-mexicana-en-el-bienio-que-como-su-rector-lagoberno-el-doctor-don-juan-de-narvaez--0/html/cdcfc210-4b98-49bd-948e-ef66e3dbbcb0_244.html 
fol. $113 \mathrm{v}$

Quando del Aguila fugunta Las propricdades aplican A lo excelfo de fu vuelo, $Y$ à lo claro de fu vifta. A quien mejor, gran Señor,

O aquien tambien la rendida Obligacion podrà cảar

Placemes de tanto dia,

Como à vos,que fois el centro Gloriofo, donde terminan De tan gran circunferencia Tantas bien tiradas lineas? A vos, en cuya Laguna Las Imperiales antiguas Sacras Aguilas renuevan Las plumas envejecidas? A vos Aguila caudal,

Cuya decendencia altiva Naciò de tantas Coronas En las Imperiales cimas: Vos, de quien fe teme ol Sol, Que quando fuluz embia Ola encubrais con las alas, $\mathrm{O}$ la agoteis con la virta: Vos, cuyos gloriofos hechos Nadie aplaudir offaria, $S$ i vueftras alas no dieran Las plumas con gुfe eferivan,
Cuyas victoriofas plantas

Al Aguila de las Indias La coronan de laureles Mas que la huellan vencida, Cuy as plumas, quando ocupan Toda la region vacia Las peyna el ayre con miedo Con refpeco el Sol las rifa: Vos Aguila de dos cuellos

Quc con equitad medida Vno mira a la piedad, $Y$ otro atiende à la jufticia: Vos que de Sol mas hermofo Atento à la luz divina Bebeis las lazes, que efparce Seguis los orbes, que gira: De aquel Sol, digo, animado

De cuyas tuzes mendiga Los broches ă campa el cielo Las galas quie oftenta el dia. De la Deidad Mantuana, Que en el ciclo es de Medina De Palas divina afrenta, De Venus fagrada embidia. Recebid defte Mufeo

Las que amantes os dedican

Ofrendas, que fon defleos Sacrificios, que fon vidas.

Dieronfele cn premio dos vandejas de plata, con que puede adornar fu efcaparatc, y con ellas fo le enbio efte Epigrama:

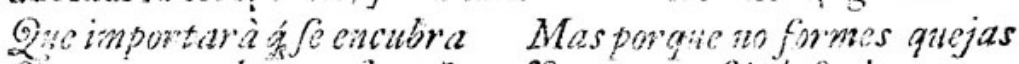
Satuzinnombre enefteträce Sicficituentaromance Ta gate te cofí丶 defoch Ay gue tu nombre defubra?

Cand à doste prenian velo Pues te bádado dos vandejas 
En el romance, el Marqués de la Laguna, Virrey de la Nueva España, es “invictísimo Cerda”, “Águila augusta”, "Gran señor”, “centro glorioso”, "águila caudal”, "cuyas victoriosas plantas/ al Águila de las Indias/ la coronan de laureles/ mas que la huellan vencida". Águila sobre águila, en este hiperbólico romance, donde vemos y veremos a la virreina a un lado del virrey. Tanto por el anagrama, descifrado desde aquellos años de 1682 y 1683, como el entrelazar lo épico con lo lírico, se descubre la mano autorial, la de Sor Juana Inés de la Cruz.

Este poema no pasó a las ediciones antiguas de España, inauguradas con Inundación Castálida de $1689^{14}$. Los "poemas humanos" que allí se publican seguramente circularon de mano en mano, mientras que las imprentas de la ciudad de México publicaron en ediciones sueltas los villancicos de la monja poeta. Fue en noviembre de 1680 su gran entrada triunfal a la vida pública eclesiástica novohispana al mismo tiempo que a la del gobierno civil: su prodigioso Neptuno Alegórico, publicado primero en México en la imprenta de Juan Rivera y en 1689 en Madrid, en su primer libro -Inundación Castálida - que primero en formato de legajos manuscritos cruzó el Atlántico para, ya de modo impreso, volverlo a cruzar.

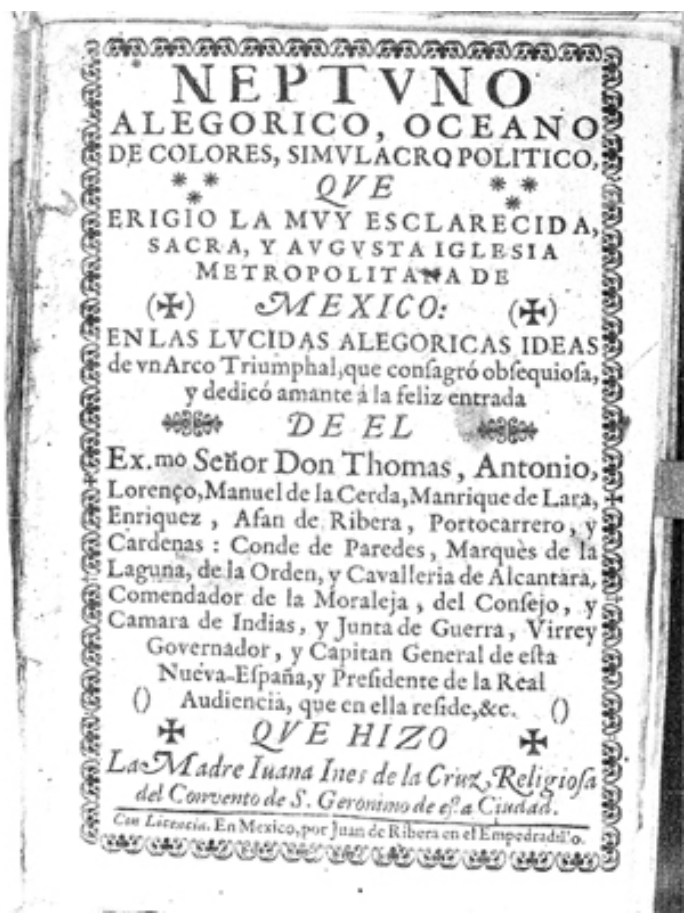

\footnotetext{
${ }^{14}$ Inundación Castálida de la Única Poetisa, Musa Dézima, Soror Juana Inés de la Cruz, Religiosa Professa en el Convento de San Gerónimo de la Imperial Ciudad de México... Dedícalos a la Excel. ma. Señora. Señora D. María Luisa Gonzaga Manrique de Lara, Condesa de Paredes, Marquesa de la Laguna. Madrid: Juan García Infanzón, 1689.
} 
El Neptuno Alegórico de 1680 era el saludo novohispano a los representantes del gobierno español. La Iglesia lo encargó a la Madre Juana Inés de la Cruz, cuyo nombre aparecía en la portada del folleto y con la magna instalación se desplegaba a la vista de todos. La presencia de su autora era rotunda. Se agotaría el tiraje que imprimió Juan de Ribera y se reeditaría nueve años después en el primer libro de la escritora novohispana publicado en Madrid, y que inauguraría una serie sorprendente y continua de ediciones.

Un acto político de esa magnitud situaba a su autora en las altas esferas de la intelectualidad española y criolla. En las 328 páginas de Inundación Castálida se habían impreso sonetos, romances, redondillas, glosas, décimas, liras, endechas, loas (sobre todo de cumpleaños), ovillejos, juegos de villancicos, que cerraban con lo que fue el sábado 30 de noviembre de 1680 la recepción de los virreyes de la Laguna, el espectacular Neptuno Alegórico,

Que hizo la Madre Juana Inés de la Cruz, Religiosa del Convento de San Gerónimo de esta Ciudad:

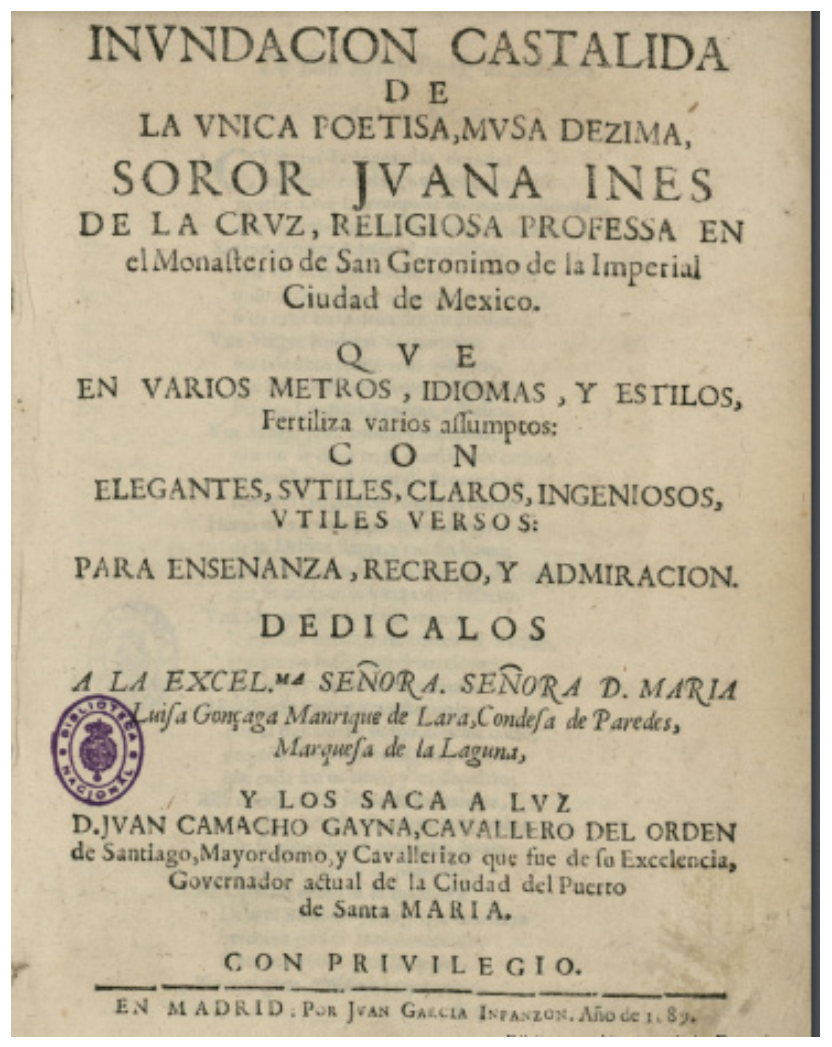


Inundación Castálida ${ }^{15}$ es -podríamos decir- el primer encuentro literario de las dos Españas vía Sor Juana Inés de la Cruz. Sus textos cruzaron el Atlántico y a fines de 1689 se reunieron en ésta, su primera edición, una de las tres originales $-1689,1692,1700$-, reproducidas una y otra vez. La antecedían ediciones sueltas publicadas en la Nueva España, las de algunos de sus primeros villancicos y la del arco triunfal de 1680, el Neptuno Alegórico. La portada de Inundación Castálida, diseñada por los editores en España, recogía la dedicatoria formulada desde la Nueva España, la de su autora que agradecía a su mecenas -María Luisa Manrique de Lara, Condesa de Paredes, Marquesa de la Laguna- la publicación del libro. La ex virreina de México (1680-1686) había tenido el genial tino, inteligencia y delicadeza de llevar a excelentes términos el inicio profesional e impreso de la fama de Sor Juana Inés de la Cruz, que cruzó el Atlántico, la historia y la geografía.

El primer poema de Inundación Castálida era el sello de agradecimiento y amistad: un soneto formal en la dedicatoria y personal en el contenido: a Lisy Divina, a quien va el encargo, la respuesta -“estos borrones"- desde la Nueva España a quien desde España solicita el oro en polvo de la poesía:

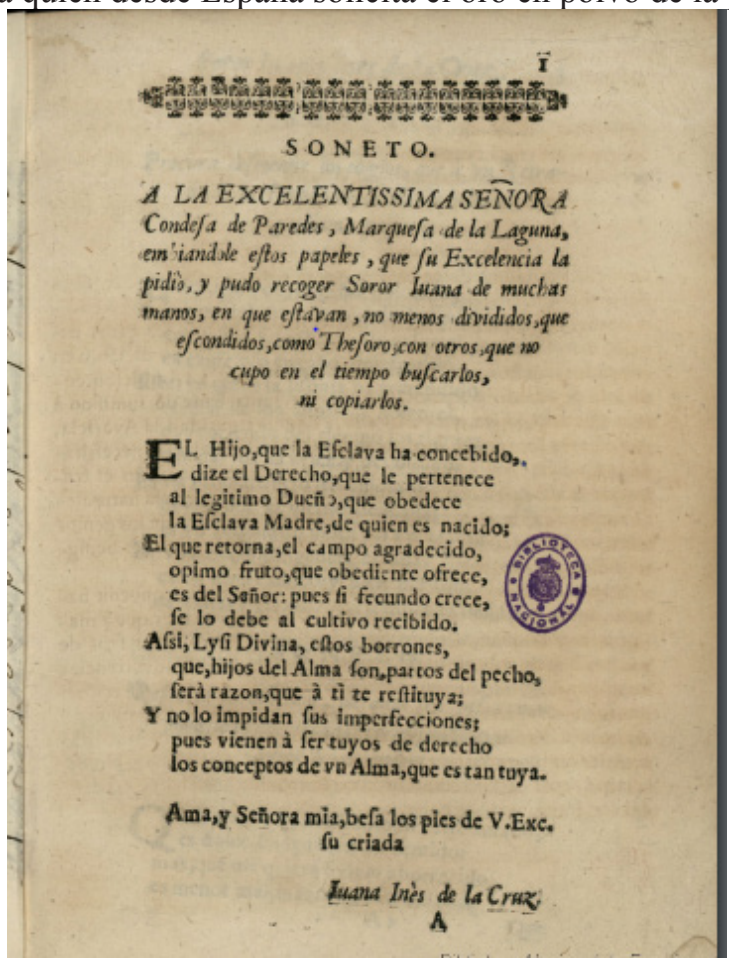

15 Copio las imágenes de la Biblioteca Nacional de España:

http://bdh.bne.es/bnesearch/CompleteSearch.do;jsessionid=0645BF65A58253CB6AE5166C3474A B61 ?showYearItems $=\&$ field $=$ todos $\&$ advanced $=$ false\&exact $=$ on\&textH $=\&$ completeText $=\&$ text $=$ sor $+\mathrm{j}$ uana + in $\%$ c $3 \% a 9 s+d e+l a+$ cruz\&languageView $=$ es \&pageSize $=1 \&$ pageSizeAbrv=30\&pageNumber=8 
Una de las recurrencias temáticas de los versos de la monja jerónima de México, sobreentendido el genio poético en un registro caleidoscópico de métricas, era el tema de los cumpleaños - del Rey de España, del virrey de la Nueva España, de las reinas y las virreinas, con María Luisa Manrique de Lara en la vanguardia. Con el deleite de la lectura, se pueden seguir además sucesos de época, una especie de calendario y posiciones de poder. En sus versos, su autora no sólo celebra sino hilvana hilos transatlánticos con visos políticos, familiares y personales. Su voz -la de su autoría- inteligentemente iba en el borde y cedía la palabra a figuras alegóricas y algunas veces a otros personajes. Uno de los ejemplos son estas:

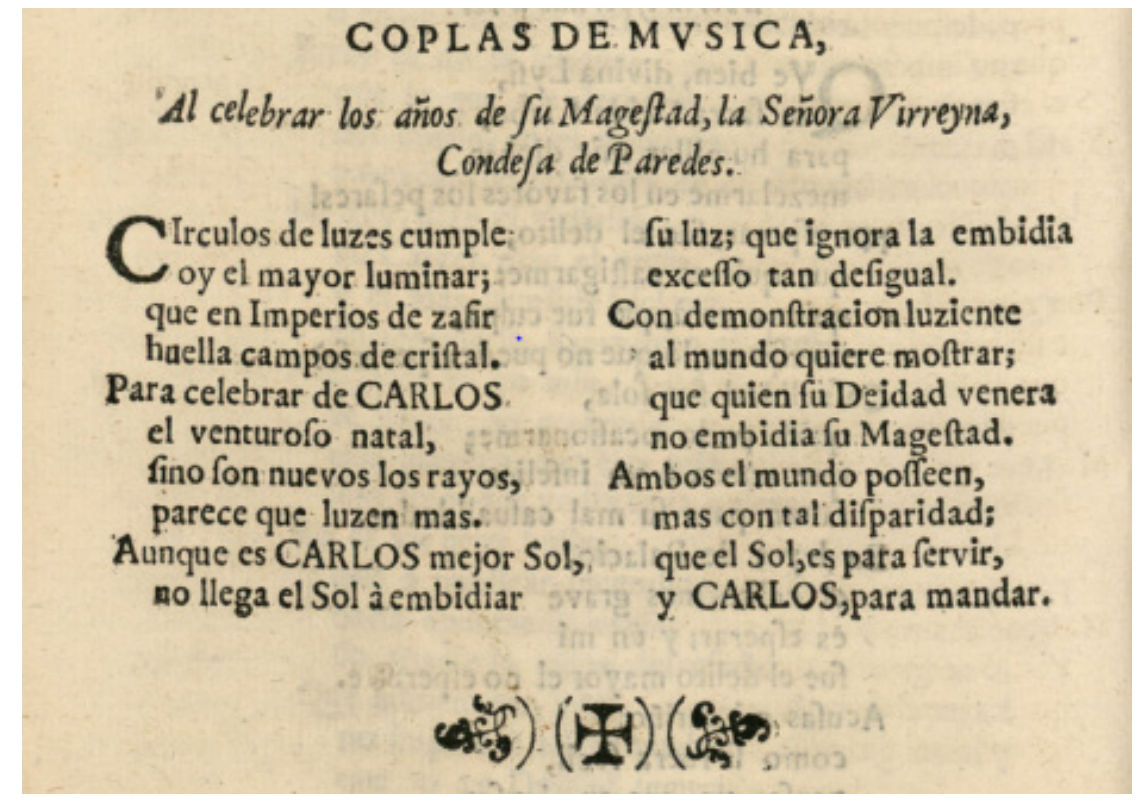

Sor Juana toma la medida a los tiempos y a su manera (no oficial) y desde el convento celebra con su poesía las conmemoraciones del regio palacio español y del palacio virreinal novohispano. A quien se festeja siempre recibe el obsequio en contexto, que también puede ser íntimo y familiar, como se ve en la felicitación al virrey de la Laguna en uno de sus cumpleaños:

\footnotetext{
Mi Señora la Marquesa,

en quien ya se conformaron,

el Cielo aspirando aromas,

vibrando luces el Prado

(IC, p. 13; MP 13, vv. 77-80, p. 42)
} 
El motivo de muchos poemas de esta publicación es el cumpleaños, también es un pretexto, y en el propio festejo poético se deja ver el entrelazamiento de España y la Nueva España.

\title{
4. España en las loas de Sor Juana publicadas en España en 1689
}

Inundación Castálida era un agasajo poético y muchos de sus poemas eran loas, un género de época de alabanza y finezas. De las loas publicadas en Inundación Castálida en Madrid (1689), sus editores decidieron poner en primer lugar la "Loa en las huertas donde fue a divertirse la Excelentíssima Señora Condesa de Paredes ("Hoy, la Reina de las luces", IC, pp 25-31; MP: 382, pp. 427-442).

En segundo lugar de Inundación Castálida está la "Loa a los felices años del señor Virrey Conde de Paredes, Marqués de la Laguna" ("Hoy es", IC, pp. 50-59; MP: 381, pp. 404-426). Como dice el título, se trata del natalicio del virrey de la Laguna, nacido en España el 24 de diciembre de 1638. Al virrey se le trata de Adonis, de Mavorte. La mitología está presente, lo mismo que la cultura marcial. Clama Belona:

\author{
Cuantos el clarín esperan, \\ que les dé militar orden; \\ cuantos al pífano atienden, \\ cuantos oyen los tambores, \\ cuantos al parche se inclinan, \\ cuantos siguen los pendones: \\ cuantos embrazan escudos, \\ cuantos enristran lanzones, \\ cuantos las bombas disparan, \\ cuantos asestan cañones; \\ cuantos sirven con ballestas, \\ partesanas, pasadores, \\ picas, bombardas, montantes, \\ mazas, anciles, estoques, \\ piezas, granadas, mosquetes, \\ lenguas, balas, culebrones, \\ arietes, pasavolantes, \\ frasqueras y municiones... (vv. 101-118)
}

El despliegue marcial - Mavorte, Marte- es un prodigio léxico detrás del cual está el conocimiento de las cosas, toda una cultura. La voz de Belona continúa: 
Toda la máquina, en fin, militar, que se compone de General, Comisarios, Tenientes, Gobernadores, Lugar-Tenientes, Alférez, Coroneles, Proveedores, Maestres de Campo, Sargentos, Hombres de armas, Pagadores, Furrïeles, Tesoreros, Vivanderos, Gastadores, Exploradores, Espías, Oficiales, Auditores (ya, oprimiendo el fuste, ocupen los dos grabados arzones; ya, en lucida infantería, estampas, a estampas, borren), ¡todos le aplaudan; y sean, porque a su ser se conformen, las voces de sus victorias, los ecos de sus pregones! (vv. 119-138)

La loa desborda entusiasmo y Venus, entre ninfas y amazonas, aclara que las cualidades no se refieren al primer Marte sino al "Cerda invisible", al "Alto Cerda", dice Belona. Entre Venus y Belona, acompañadas de coros, debaten acerca del amor y de la fuerza. Necesariamente llega la figura de Concordia para conciliar el valor de Marte que propone Belona con la gala, propuesta por Venus. También de Belona se escucha:

\author{
Pedidle al Cielo que eterno \\ goce América el gobierno, \\ porque tanto bien reciba \\ como el gran Cerda viva, \\ en quien ha unido el primor, \\ de Adonis la gala, de Marte el valor (vv. 432-437)
}

El resultado de la petición tiene como beneficios un gobierno gentil y valiente para la Nueva España. Ah, el virrey no está solo. A las vivas de Venus:

Viva su bella Esposa, porque admiremos que tienen las Deidades visible objeto (vs. 472-475) 
A la pareja virreinal se le desea "Sucesores", "Herederos" y la loa va llegando a su fin cuando la Concordia se dirige a la virreina, "Y vos, Divina Señora" (v. 496), y Coros, Belona y Venus continúan haciéndolo. La pieza laudatoria comenzó hablando del virrey, luego se dirige a la virreina para concluir deseándoles vida eterna. La loa en voz de damas recorre lo correspondiente a un buen gobierno, relacionado a la vez con la vida personal y familiar de los virreyes: armas, belleza, gobierno, amor, familia. Todo en boca de Damas quienes al final le hablan a la virreina, para cerrar con vivas a la familia del virrey, que ese día -24 de diciembre- cumplía años. El 30 de noviembre de un año antes -1680-, el marqués de la Laguna había asumido oficialmente el virreinato de la Nueva España; María Luisa, su esposa, daría a luz en julio de 1683. La loa les desea herederos y no hay indicios de que María Luisa estuviera embarazada. Luego la loa pudo ser de diciembre de 1681. Lo que es rotundo: la genialidad de Sor Juana Inés de la Cruz, que escribe una loa con conocimientos mitológicos, de las artes marcianas (¡impresionante su saber!), que propone un gobierno valiente y gentil para la Nueva España, que da "entrada triunfal" a la virreina, que desea un heredero para ellos, que hace votos por una vida feliz a quien gobierna la Nueva España: deseo que, al mismo tiempo, va con indicios de deberes y responsabilidad, lo que se espera por parte del virrey.

La tercera loa que aparece en Inundación Castálida (1689) es la "Loa a los años de la reyna N. Señora Doña María Luisa de Borbón" (IC, pp. 65-73; MP, 379, pp. 376-393, 451 versos). Cuando Sor Juana la escribe, aún vivía la joven reina María Luisa de Orléans; sin embargo, cuando los manuscritos circulan entre quienes darían el visto bueno para la publicación ${ }^{16}$, la joven reina ("de su edad florida y tierna") ya había muerto: 12 de febrero de 1689. Es una loa de cumpleaños. Se dice que nació el 26 de marzo de 1662; también que el 26 de abril de 1662. En la loa de Sor Juana se lee: "hoy a su Abril florido" (v. 260). ¿Mejor manera de referirse al paso de María Luisa de Francia a España que estos versos de Sor Juana: "pasó a Rosa de Castilla,/ siendo flor de lis francesa"? (vv. 67-69). Se mencionan las relaciones de los Austrias, Borbones y de Alemania, España y Francia, "que en mutua correspondencia,/ por Francia obligan a España,/ y a España por Francia empeñan” (vv. 90-92). También al

${ }^{16}$ Aprobación del Revmo. P. M. Fr. Luis Tineo de Morales, del Orden de Canónigos Reglares Premonstrarenses, Maestro General de su Religión, Predicador de su Magestad, y su Theólogo de la Real Junta de la Purísima Concepción, Abad del Convento de San Joachin de esta Corte: Firma en Madrid, agosto 20 de 1689. Licencia del Ordinario del Lic. D. Alonso Portillo y Cardos, Vicario de esta Villa de Madrid: 22 de agosto de 1689 (por su mandado, Christóval de Zepeda). Aprobación del Reverendíssimo Padre Diego Calleja, de la Compañía de Jesús: Madrid, 12 de septiembre de 1689. Suma del privilegio: Madrid, 19 de septiembre de 1689 [Varios poemas castellanos de Soror Juana Inés de la Cruz]. Fee de erratas: Madrid, 17 de noviembre de 1689. Suma de la Tassa: Madrid, 19 de noviembre de 1689. 
"Católico Monarca", a la "divina Mariana", y al "invictísimo Cerda", virrey de la Nueva España de 1680 a 1686. ¿Sería esa loa anterior al año en que el marqués de la Laguna dejaría de ser virrey? Cuando se publica la loa en Inundación Castálida (tal vez a fines de 1689), la mención del (ex) virrey de México sería importante en los círculos de poder (político y letrado), que el aplauso venía de la Nueva España, al mismo tiempo que la loa quedaría como una especie de homenaje - de memoria, como una de las mismas figuras de la alegoría - a la joven reina que ya había muerto, a quien Sor Juana loaba en los versos y música de su loa:

\author{
Viva para que los dos \\ Mundos la sirvan a un tiempo, \\ breve círculo a sus sienes, \\ y globo a sus pies pequeños (vv. 357-360)
}

La visión poética menciona el pasaje de transición de María Luisa: de Francia a España, y las "vivas" se hacen en vida de la reina, quien moriría el año cuando se publica la loa. Se ha escrito acerca de María Luisa de Orléans. ¿Quiénes más escribirían de ella mientras vivía? Sor Juana lo hizo desde la Nueva España; la loa apareció impresa en España en 1689, a varios meses de haber muerto la reina. ¿Quién repararía en esta situación?

¿Loas al rey? A partir de una primera (cuarta en Inundación Castálida) hay una ristra de loas dedicadas a Carlos II. La primera es la "Loa en celebración de los años del Rey Nuestro Señor ("Hoy al clarín de mi voz/ todo el Orbe se convoque" (IC, pp. 86-93; MP: [I], 374, pp. 279-294, 393 vs.). Entre los parlamentos del Fuego, el Aire, el Agua y la Tierra, dos coros celebran el "Hoy" del cumpleaños y, con la música, el amor y el cielo, y loan de modo excelso a Carlos II, rey de España. Un rasgo sobresale: la relación de España con la Nueva España. Clama el Cielo:

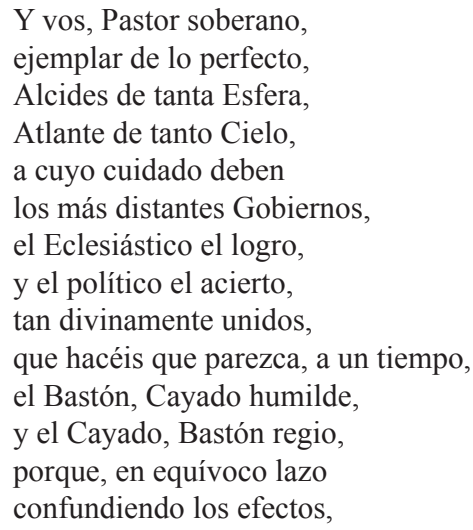


amor el Bayón infunda,

cause el Cayado respeto (vv. 310-325)

Cielo le habla a Fray Payo de Rivera, virrey arzobispo de la Nueva España de fines de 1673 a fines de 1680 (antes de que llegara el Marqués de la Laguna). Cuando Sor Juana escribe esta loa, el joven Carlos II aún no se casaba con María Luisa de Orléans, lo que fue en 1679. La loa sería, sugiere en sus Notas Méndez Plancarte (III, p. 652), entre 1674 y 1679.

La segunda es la "Loa al mismo assumpto": "A los años alegres y festivos" (IC, pp. 93-100), que Méndez Plancarte anota como V (378; pp. 359-376). A las cualidades de Carlos II, quien "veintitrés cabales años/ cumple de su edad dichosa" (vv. 170-171), entre otras su generosidad, se unen las de su esposa: "Y la sagrada María,/ clara emulación del día/ vuestra Esposa generosa" -dice la Luna (vv. 360-362) - ¡viva gloriosa! -remata la Música (v. 363). Mientras el Sol proclama: "Viva la Nobleza y Plebe,/ a quien nuestro Carlos debe/ tanta aclamación gustosa" (vv. 408-410). Carlos comparte la gloria de su reinado con María Luisa, visible en la loa de Sor Juana, y se le aclama por su reinado equitativo. La loa sería de noviembre de 1679.

Y una tercera (la sexta en $I C$ ): "Loa al mismo assumpto": "Aunque de la vida son/ por fuerza todos los días" (IC, pp. 100-108; MP: [II], 375; pp. 295312). La voz de Majestad, nombra a la esposa del rey:

\author{
Y pues la Francesa \\ Flor de Lis divina, \\ que trasplantó a España \\ su pompa florida, \\ vive, porque goza \\ vuestra compañía (vv. 421-426)
}

La Vida se refiere a la Reina Madre: "Y el Águila sacra/ de Mariana invicta" (vv. 429-430). La monarquía española se extiende a la Nueva España en boca de Lealtad:

Y el Cerda invencible,

que él solo acredita

vuestro Imperio, más

que la Monarquía,

pues vive en vos como

vuestra Sangre misma (vv. 437-440).

El "invicto" virrey vendría acompañado de su consorte. Dice Naturaleza: 


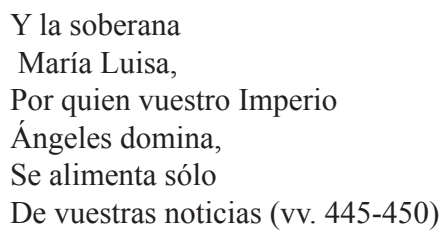

El cumpleaños da lugar a un texto y éste a un pretexto para configurar a los personajes masculinos y femeninos de la monarquía que gobierna España y la Nueva España. La loa sería entre 1681 y 1685. No aparece como loa suelta puesto que para finalizar, incluyendo antes a las Damas de Palacio, se anuncia una comedia. Primero dice la Plebe: "Yo os diré; que cansados/ de ver Loa tan prolija,/ empiezan ya la Comedia" (vv. 485-487). La Lealtad dice que las Damas están ocupadas y que no es posible. Entonces, la Plebe anuncia:

\author{
Pues \\ ¡buen remedio! Pues vestidas \\ estáis, vosotras podéis \\ hacerlas. Pues si me dicta \\ bien el magín, la Comedia \\ todas las tenéis sabida, \\ que es una de Calderón, \\ que dice que es, en la Vida, \\ Verdad y Mentira todo (vv. 491-499)
}

La loa termina cuando siguiendo a Naturaleza, aclaman Música y todos: “¡Vivan Carlos y María!” (v. 515). La comedia pudo ser de 1681 o de 1682.

Una cuarta loa dedicada al rey (la octava en Inundación Castálida) es la "Loa, a los años del Rey Nuestro Señor Carlos Segundo, que celebra Don Joseph de la Cerda, Primogénito del Señor Virrey Conde de Paredes" (“A1 luminoso Natal/ del Sol Hispano Monarca". IC, pp 143-153; MP: [IV], 377; pp. 331-358 $)^{17}$. Sor Juana cede su lugar al pequeño hijo de los virreyes de la Laguna, quien había nacido en julio de 1683 en la Nueva España, para ahora celebrar al rey de España. De "natal novohispano" al "natal hispano". La loa, envuelta de ramos de hojas, frutas, árboles, fuentes y aves, celebran a Carlos.

\footnotetext{
${ }^{17}$ Las otras dos loas que aparecen en Inundación Castálida son ( $7^{\mathrm{a}}$ ) la "Loa, al año, que cumplió el señor Don Joseph de la Cerda, Primogénito del Señor Virrey, Conde de Paredes" ("Si la Tórrida, hasta aquí..." IC, pp. 122-130; MP: 383; pp. 442-462); otra ( $\left.8^{\mathrm{a}}\right)$ es la "Loa, a los años del Reverendísimo P.M.Fr. Diego Velázquez de la Cadena; representada en el Colegio de San Pablo" (IC, pp. 157-165; MP: 385, pp. 483-502). Una de las iniciales, la "Loa de la Concepción", que comienza con "Sagrado asunto en mi voz" (de los años setenta del siglo de Sor Juana), aparecerá en el Segundo volumen de Sevilla (1692; MP: 373, pp. 259-279), lo mismo que la "Loa a los años de la reina madre", "Al feliz natalicio" (MP: 380, pp. 394-403); una más, para el rey Carlos II (MP: [III], 376; pp. 313-330, "Escuche mi voz el Orbe"... "Pues siendo hoy Seis de Noviembre") y el "Encomiástico poema a los años de la Condesa de Galve” (MP: 384, pp. 462-482).
} 


\section{Le dice Eolo:}

(que aunque parecéis ausente, no lo estáis, que a la lealtad nunca hay ausencia en los Reyes;

y así, aunque parece que lo estáis, Señor, atendedme como muy presente, porque os tengo yo muy presente) (vv. 353-359)

José es reflejo:

de Joseph en nombre; porque solamente es bien que a José luces representen (vv. 410-413)

\section{Reflejo dice:}

"fuerza es que la imagen/ de Carlos se muestre/ en la Real Laguna" (vv. 454456)

y dice también:

La Francesa Venus, que en belleza excede a la que de Adonis lamentó la muerte (vv. 559-562)

\section{Y sigue la Música:}

“que sí en sí tiene/ Imperio más alto/ que Carlos posee (vv. 563-565).

\section{Y dice Siringa:}

La gran Marïana, que, en que Carlos reine, goza el privilegio de reinar dos veces (vv. 566-569)

\section{Y Pan continúa:}

Y el Cerda invencible, en quien resplandece el resplandor claro 
de su Real Progenie (vv. 573-576)

Y Flora prosigue:

Y la alta María, tan divina siempre, que de humana sólo lo visible tiene (vv. 580-583)

Y Reflejo nombra:

y el José glorioso que, en su tierno Oriente, este obsequio corto a su Rey ofrece (vv. 587-590)

Y celebran el docto Senado, los Tribunales, los Reales Ministros, las bellas Damas. La Siringa resume:

\author{
y la Gran Ciudad, \\ la Nobleza y Plebe, \\ leal cuerpo de tantos \\ timbres diferentes (vv. 606-609)
}

La figura de José, "el mexicano" (por haber nacido en México), reúne los "timbres diferentes" de la loa. Es una loa de noviembre de 1683, a unos meses de nacido el hijo de los virreyes. Las cuatro loas dedicadas a Carlos II, al parecer año con año, conforman una materialidad ("loable" también) en Inundación Castálida. Se conforma una imagen de la España monárquica construida desde la Nueva España: el acto poético cede a un acto político.

En sus loas, Sor Juana manifiesta su visión sobre todo acerca del aparato virreinal, del palacio español al novohispano. Además de la configuración de la figura del rey, a quien no sólo se le dedican loas, de su primera esposa María Luisa, incluso de la reina madre, está presente la pareja conformada por el marqués de la Laguna y la condesa de Paredes. Las loas son prueba de que en el gobierno de la Nueva España es muy importante la figura del rey y la lealtad de virrey que lo representa, lo que se hace por medio de líneas elogiosas, propias de aquel género de época, al mismo tiempo que líneas digamos personales, familiares, que rompen con el formalismo de dicho género y refuerzan su fin político.

Es importante notar que, en el gran puente colgante que atraviesa con sus versos el Atlántico, hay un ancla poderosa de este lado de América, respecto a la identidad de la poeta. En la lectura de su genealogía nacida en España, 
enraizada y multiplicada en la Nueva España, en la relación que la voz poética hace entre el reinado y el virreinato, en el entresijo de discursos poéticos, familiares y personales - cada uno con lo propio y a la vez como parte de un telar de hilos distintos bordados en la escritura- hay, entre otros, un romance en que se explicita una identidad por parte de su autora. Se trata del Romance Aplaude lo mismo que la Fama en la Sabiduría sin par de la Señora Doña María de Guadalupe Alencastre, la única Maravilla de nuestros siglos: (IC, pp. 132-135. MP: 37, pp. 100-101). Luego de una escala de adjetivos plenos de admiración dirigidos todos a la "Grande Duquesa de Aveyro", digna de todos ellos, entre otros los tan citados:

claro honor de las mujeres, de los hombres docto ultraje, que probáis que no es el sexo de la Inteligencia parte (vv. 29-32)

Sor Juana (re)marca el lugar desde donde escribe, "desde la América”, su condición "desinteresada", su orgullo de nación:

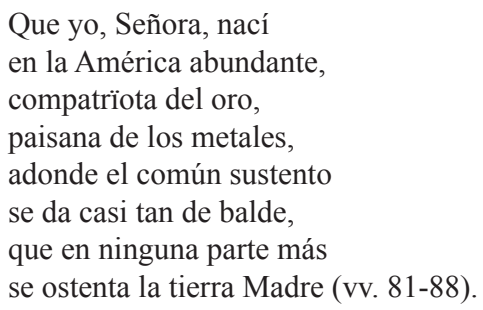

El "yo" de la voz poética es su signo de "nación", de nacimiento, a la vez que califica la riqueza sinigual de dicha (y dichosa) tierra:

Europa mejor lo diga,

pues ha tanto que, insaciable,

de sus abundantes venas

desangra los minerales (vv. 93-96)

La denuncia del saqueo es contundente, aunque no se necesita decirlo. Aun así, se dice, lo dicen las líneas del romance, lo dice la voz poética, lo dice la poeta "americana", mexicana, criolla en segunda generación, española y arraigada en su patria. Y sigue hablando "en voz alta", en la escritura silenciosa (épica y lírica, "épica sordina") de sus versos: 


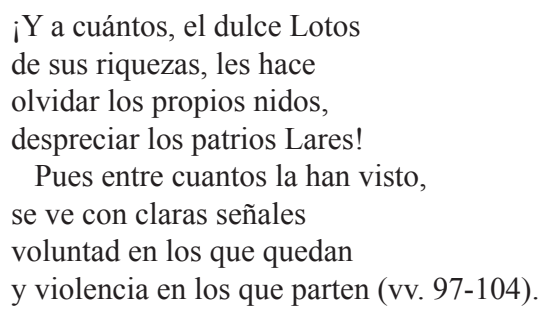

Llegar, quedarse, pertenecer, sería ésa su propuesta, hecha -dice- "en el estado/ que Dios fue servido darme", un estado de renuncia a las cosas (pero no a las palabras):
¿Pero a dónde de mi Patria
la dulce afición me hace
remontarme del asunto
y del intento alejarme?
Vuelva otra vez, gran Señora,
el discurso a recobrarse
y del hilo del discurso
los dos rotos cabos ate (vv. 125-132).

La voz poética, reflejo de la visión de la poeta, "recobra" el discurso y escribe "de hinojos" (aunque no lo dice así) "a pesar de tantos mares" (v. 136). Se evoca de inmediato a Nueva España: "La siempre divina Lysi" (v. 137), virreina de la Nueva España, quien al escribirle a su prima Guadalupe de Alencastre a fines de 1682, le habló "de una monja que hay en san Jerónimo que es rara mujer no la hay", quien "habiéndose criado en un pueblo de cuatro malas casillas de indios trujéronla aquí y pasmaba a todos los que la oían porque [fol. 7r] el ingenio es grande" (Calvo \& Colombi 2015). La virreina fue intermediaria entre la duquesa y la poeta: tres mujeres en un momento que trascendería (además) en Portugal con las monjas de La Casa del Placer, con quienes Sor Juana estableció lazos de amistad poética (lo que aquí sólo menciono).

Fue María Luisa Manrique de Lara quien le solicitó a Sor Juana el Auto sacramental que sería representado en Madrid: El Divino Narciso. Al final de la loa que acompaña al auto sacramental se dice, Celo (personaje alegórico) dice, pregunta: “¿Y dónde se representa?” (v. 435). Religión contesta:

\footnotetext{
En la coronada Villa

de Madrid, que es de la $\mathrm{Fe}$

el centro, y la Regia Silla

de Católicos Reyes,

a quien debieron las Indias
} 
las luces del Evangelio

que en el Occidente brillan (vv. 436-442)

Si no hubo tal representación en Madrid, como advirtió Georgina Sabat de Rivers, la loa y el auto sacramental fueron ideados para que sí lo fuera. La loa que antecede al auto sacramental es un acto conciliatorio mediante los diálogos de América y Occidente con Religión y Celo. La propuesta patente, mediante la argumentación de las figuras alegóricas, es la conciliación: las armas ceden a las palabras, el campo semántico creado por Sor Juana Inés de la Cruz.

En su proceso creativo, la poeta novohispana respetó jerarquías, entendió las relaciones de poder e, incluso, participó en ellas, sobre todo en cuanto al prestigio intelectual. Sin embargo, ese proceso llevaba consigo una especie de independencia: practicar las reglas para transformarlas, liberar las formas, mezclar géneros de su época, subvertir con el propio arte, una vez dominado, como ella misma hizo con la esgrima de su arte. Y, sobre todo, ser libre, como ella misma lo fue, aun en los intramuros del convento, en una sociedad altamente masculina, inequitativa. ¿Cómo lo logró? Al prodigio de su talento intelectual, de su perspectiva de las cosas, de su don natural y capacidad de entendimiento, se unió su disciplina, su estudio, su sacrificio, su estar despierta, como se manifiesta en el último verso de su Primero Sueño.

\section{5. "Qué mágicas infusiones"}

Sor Juana Inés de la Cruz fue famosa en su tiempo y lo sigue siendo en el nuestro. Sus primeras ediciones se publicaron (las sueltas) en la capital de la Nueva España y (las primeras ediciones antiguas) en la capital de España. La excepción respecto al lugar de la publicación fue la Carta Athenagórica (1690), esto es, la Crisis sobre un sermón (1692). La primera se publicó en la ciudad de Puebla y la segunda en Sevilla, lo que sería motivo de otras reflexiones.

Víctima de una epidemia, Sor Juana Inés de la Cruz murió en el Convento de San Jerónimo de la Ciudad de México. Eso fue en la madrugada del domingo 17 de abril de 1695. Cinco años después, se publicó en Madrid la Fama y Obras pósthumas (1700). Allí leemos su romance: En reconocimiento a las inimitables Plumas de la Europa, que hicieron mayores sus Obras con sus elogios: que no se halló acabado (pp. 157-162 ${ }^{18}$; MP 51, pp. 158-161):

¿Cuándo, Númenes divinos,

dulcísimos Cisnes, cuándo

${ }^{18}$ Una nota dice: "Este Romance, que aun entre la valentía de los números, muestra en la Poetisa lo humilde de su genial desconfianza, se halló así, después de su muerte, en borrador, y sin mano última" (p. 126; aunque aparece como p. 162).

Araucaria. Revista Iberoamericana de Filosofia, Política, Humanidades y Relaciones Internacionales, año $23, \mathrm{n}^{\circ} 47$. Segundo cuatrimestre de 2021. Pp. 131-162. ISSN 1575-6823 e-ISSN 2340-2199 https://dx.doi.org/10.12795/araucaria.2021.i47.07 
merecieron mis descuidos

ocupar vuestros cuidados?

¿De dónde a mí tanto elogio?

¿De dónde a mí encomio tanto?

¿Tanto pudo la distancia

añadir a mi retrato? (vv. 1-8)

Emocionada con los censores de lo que sería el Segundo volumen de sus obras, en su discurso poético se pregunta y pregunta sobre cómo es posible tanta alabanza. A ella, "ignorante mujer"... "ise dirigen los elogios/ de los Ingenios más claros/ que en Púlpitos y en Escuelas/ el mundo venera sabios?" (vv. 45-48). Con su emotivo extrañamiento por lo que han provocado sus textos, escribe:

\author{
¿Qué mágicas infusiones \\ de los Indios herbolarios \\ de mi Patria, entre mis letras \\ el hechizo derramaron? (vv. 53-56) ${ }^{19}$
}

Su pregunta es una interrogación, una admiración, un reconocimiento, un pacto de identidad con México y sus raíces originarias. Sor Juana Inés de la Cruz comenzó a escribir este romance de agradecimiento al recibir el Segundo volumen de sus obras, publicado en Sevilla en 1692. Lo recibiría en la segunda mitad del año y lo pondría junto a sus otros libros, propios y ajenos. ¿Ajenos?, no. Se los había apropiado desde el oficio profesional de sus lecturas de tantos años y de los que se desapropiaría, incluso de los suyos, en los últimos años de su vida. Por suerte, la mayor parte de su escritura se había impreso en España y antes, aunque en grado menor, en la Nueva España. A más de trescientos años de haber sido escritos, puede darse el milagro de que salgan a la luz algunos de sus manuscritos, ya sea en México, en España o en lugares insospechados.

\title{
6. Recientes y esperanzadoras noticias
}

El 24 de mayo de 2021, en Uruguay apareció un retrato de faltriquera de la duquesa de Aveyro $^{20}$, a quien María Luisa Manrique de Lara, condesa de Paredes, le habló de Sor Juana y a quien Sor Juana le compuso un romance, ya aquí citado. Este hallazgo reciente es una esperanza para posibles nuevos

\footnotetext{
${ }^{19}$ Informa Enrique Flores: "En el siglo XVII la Patria es 'el lugar, ciudad o país, en que se ha nacido" (Aut.). Y si Sor Juana escribe 'los indios herbolarios de mi patria', habla de los indios xochimilcas de la región de San Miguel Nepantla, el 'lugar' en que había nacido", en "Sor Juana y los indios: loas y tocotines". Literatura Mexicana 18.2 (2007): 39-77.

${ }^{20}$ Entre otras noticias, https://www.efe.com/efe/america/cultura/un-retrato-intimo-de-la-duquesaaveiro-cobra-vida-en-uruguay/20000009-4544319
} 
hallazgos de y sobre Sor Juana Inés de la Cruz. "Dios nunca muere", dice la canción. Sor Juana, tampoco. Por su obra, sus escritos, su libertad, su genialidad, prodigio en las letras (y también de los números). Nacida en México, criolla, americana, mexicana y consciente de diferencias raciales y sociales, Juana Ramírez de Azuaje -Sor Juana Inés de la Cruz- fue genio de época y lo sigue siendo.

En la Fama y Obras pósthumas de 1700, al hablar de Sor Juana, Diego Calleja concluyó: "Llenas las dos Españas con la opinión de su admirable sabiduría" [p. 15, ya citada]. En la respuesta de un indio al fraile dominico Diego Durán (siglo XVI), leemos: "Padre, no te espantes pues todavía estamos nepantla". Un siglo después (siglo XVII), Sor Juana seguía en Nepantla, en Panoayan (allí en Amecameca), en la Ciudad de México, en Madrid, en la Nueva España, en otros virreinatos, en España y sus autonomías. Ahora, en “todas" partes. Y lo está con su obra. Lo sigue y seguirá estándolo. Su Nepantla es un estar en uno, en otro lugar, en los suyos, los tuyos, en los nuestros. Es una " $y$ ", una conjunción permanente, aquella "Y diversa de mí misma/ entre vuestras plumas ando", de aquel "romance que no se halló acabado". En España, en la Nueva España y demás: Sor Juana Inés de la Cruz. Su propuesta, una conciliación de géneros y culturas..

\section{Bibliografía}

Calvo \& Colombi 2015: Hortensia Calvo y Beatriz Colombi (eds.), Cartas de Lysi. La mecenas de Sor Juana Inés de la Cruz en correspondencia inédita (Madrid: Iberoamericana, Frankfurt: Vervuert, México: Bonilla Artigas Editores, 2015).

Flores, Enrique 2007: "Sor Juana y los indios: loas y tocotines. Literatura Mexicana 18.2 (2007): 39-77.

Robles 1972: Antonio de Robles, Diario de sucesos notables (1665-1703), t. I. Ed. Antonio Castro Leal. $2^{a}$ ed. (México: Editorial Porrúa, 1972).

Schmidhuber 2017: Guillermo Schmidhuber de la Mora, "Origen canario del padre de Sor Juana Inés de la Cruz" (Revista de Historia Canaria 199, 2017).

Sor Juana 1951: Sor Juana Inés de la Cruz, Obras completas de Sor Juana Inés de la Cruz, t. I: Lírica personal. Ed. Alfonso Méndez Plancarte (México: Fondo de Cultura Económica, 1951).

Sor Juana 1952: Sor Juana Inés de la Cruz, Obras completas de Sor Juana Inés de la Cruz, t. II: Villancicos y letras sacras. Ed. Alfonso Méndez Plancarte (México: Fondo de Cultura Económica, 1952).

Sor Juana 1955: Sor Juana Inés de la Cruz, Obras completas de Sor Juana Inés de la Cruz, t. III: Autos y loas. Ed. Alfonso Méndez Plancarte (México: Fondo de Cultura Económica, 1955).

Sor Juana 1957: Sor Juana Inés de la Cruz, Obras completas de Sor Juana Inés de la Cruz, t. IV: Comedias, sainetes y prosa. Ed. Alberto G. Salceda (México: Fondo de Cultura Económica, 1957). 


\section{Obras originales referenciadas en notas al pie de página:}

Fama y Obras Pósthumas del Fénix de México, Décima Musa, Poetisa Americana, Sor Juana Inés de la Cruz, religiosa professa en el Convento de San Gerónimo de la Imperial Ciudad de México. Ed. Juan Ignacio Castorena y Ursúa (Madrid: Imprenta de Manuel Ruiz de Murga, 1700).

Inundación Castálida de la Única Poetisa, Musa Dézima, Soror Juana Inés de la Cruz, Religiosa Professa en el Convento de San Gerónimo de la Imperial Ciudad de México... Dedícalos a la Excel.ma. Señora. Señora D. María Luisa Gonzaga Manrique de Lara, Condesa de Paredes, Marquesa de la Laguna (Madrid: Juan García Infanzón, 1689).

Ribera, Diego de. Poética descripción de la pompa plausible que admiró esta nobilisima Ciudad de México en la suntuosa dedicación de su hermoso, magnifico, y ya acabado templo, celebrado jueves 22 de diciembre de 1667, conseguida en el feliz y tranquilo gobierno del virrey Marqués de Mancera (México: Francisco Rodríguez Lupercio, 1668).

Segundo volumen de las obras de Soror Juana Inés de la Cruz, monja profesa en el Monasterio del Señor San Gerónimo de la Ciudad de México, dedicado por su misma autora a D. Juan de Orué y Arbieto Cavallero de la Orden de Santiago (Sevilla: Tomás López de Haro, 1692). 